\title{
Case report. Paraffinoom van de penis na injectie met kanamycinezalf
}

\author{
Leonie Exterkate · Jean-Paul A. van Basten
}

Published online: 16 January 2020

(C) The Author(s) 2020

Samenvatting In dit case report worden twee patiënten besproken met een symptomatisch paraffinoom van de penis (scleroserend lipogranuloom) na injectie van kanamycinezalf in de penis. Het penisparaffinoom is een zeldzame oorzaak van een zwelling die ontstaat na injectie van olieachtige substanties, paraffine, vaseline, antibiotische zalf of siliconen in de penisschacht ten behoeve van penisvergroting en kan ernstige complicaties geven zoals infecties, necrose en erectiele disfunctie. Dergelijke injecties worden met name in Oost-Europa en Azië geregeld toegepast. Hoewel een paraffinoom relatief zeldzaam is, neemt de incidentie in Nederland toe ten gevolge van een toenemend aantal migranten uit met name Oost-Europa. Behandeling bestaat uit complete chirurgische granuloomexcisie, inclusief de huid.

Trefwoorden paraffinoom - lipogranuloom • kanamycine

\section{Case report. Penile paraffinoma after injection with kanamycin ointment}

\begin{abstract}
In this case report we present two patients who developed symptomatic penile paraffinoma after self-injection with kanamycin ointment. Penile paraffinoma (sclerosing lipogranuloma) is a rare cause of a mass that can occur after injection of oil-based substances, paraffin, antibiotic ointment or vaseline into the penile shaft for penile augmentation and can cause serious complications such as infections, necrosis and erectile dysfunction. The geographic distribution of this practice is concentrated in Asia and Eastern Europe. Although penile paraffinoma can be rare,
\end{abstract}

L. Exterkate $(\triangle)$ · J.-P. A. van Basten, PhD

Afdeling Urologie, CWZ, Nijmegen, Nederland

l.exterkate@cwz.nl incidence is increasing due to migration of people from Eastern Europe in particular. Definitive management includes complete surgical excision with reconstruction as required.

Keywords paraffinoma $\cdot$ lipogranuloma $\cdot$ kanamycin

\section{Introductie}

Het penisparaffinoom (scleroserend lipogranuloom) is een zeldzame oorzaak van noduli die ontstaan na injectie van olieachtige substanties, paraffine, vaseline, antibiotische zalf of siliconen in de penisschacht, die is uitgevoerd ten behoeve van penisvergroting. Ondanks de destructieve gevolgen en late complicaties worden deze injecties in Oost-Europa en Azië nog steeds toegepast. Wij presenteren twee casus van patiënten met ernstige complicaties na zelfinjectie met kanamycinezalf in de penis. Kanamycine behoort tot de groep aminoglycoside antibiotica die vooral werkzaam zijn bij infecties met aerobe Gram-negatieve bacteriën. Het middel kan lokaal (als crème of zalf), intraveneus of intramusculair worden gebruikt.

\section{Casus 1}

Een 26-jarige mannelijke patiënt uit Roemenië met in zijn medische voorgeschiedenis een circumcisie, was door de huisarts naar de Spoedeisende Hulp verwezen in verband met verdenking op een parafimose. De patiënt had circa vijf maanden daarvoor zelf kanamycinezalf in zijn corpora cavernosa geïnjecteerd om zijn penis te vergroten. Bij navraag bleek hij instructies gekregen te hebben van zijn oom, die hetzelfde enkele jaren geleden had gedaan. Volgens de patiënt ontstond hierna een blijvende lichte zwelling van zijn glans penis. Sinds enkele dagen was de zwelling verder toegenomen en pijnlijk. Patiënt kon niet goed 


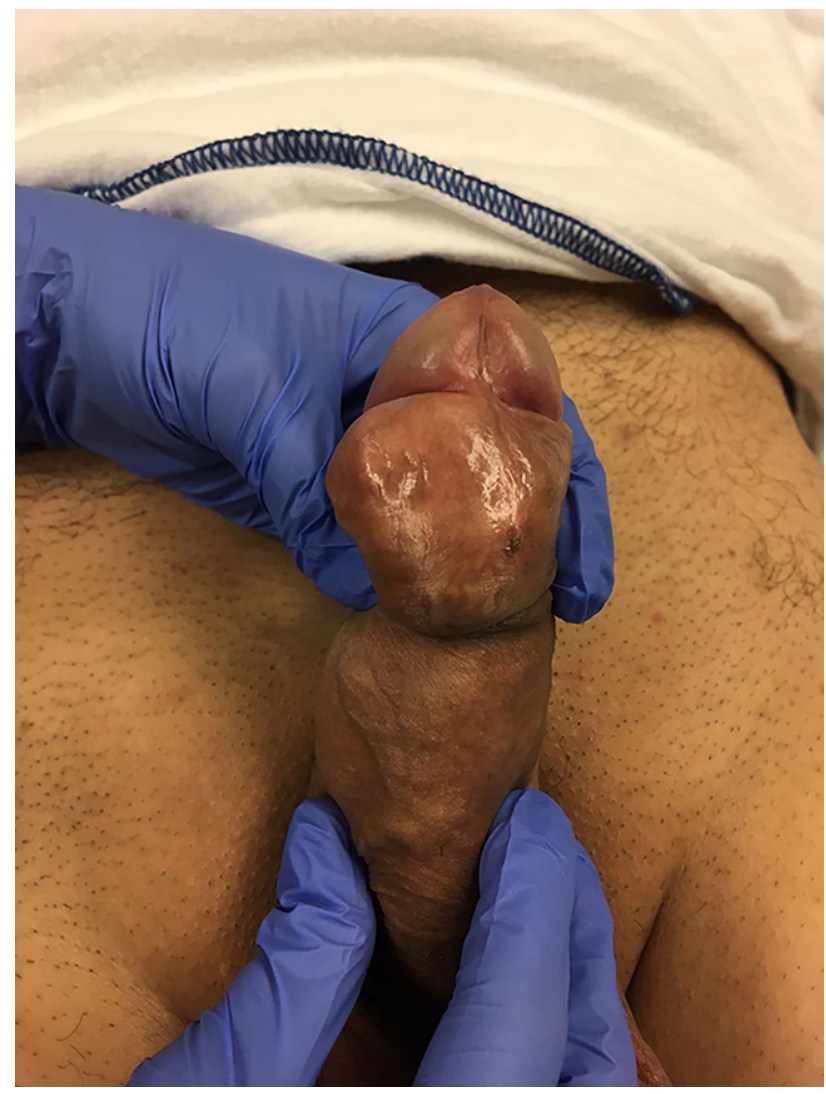

Figuur 1 Klinisch beeld van een penisparaffinoom

meer plassen. Bij genitaal onderzoek werd fors oedeem van de glans gezien met aan de dorsale zijde fibrotische plaques met een doorsnee van circa $2 \mathrm{~cm}$, net proximaal van de corona, losliggend van de corpora. Op grond van anamnese en klinische beeld werd de diagnose 'lymfoedeem bij uitgebreide paraffinomen van de penis na zelfinjectie van kanamycinezalf' gesteld. Onder lokale anesthesie werden de plaques geëxcideerd, waarbij zich een geelwitte substantie ontlastte. Vanwege de mictieklachten ten gevolge van de zwelling werd een transurethrale katheter geplaatst, die een week later probleemloos werd verwijderd. Bij cystoscopie werden geen intra-urethrale afwijkingen gezien. De patiënt verhuisde enkele weken later naar het buitenland.

\section{Casus 2}

Een 42-jarige mannelijke patiënt uit Roemenië met blanco medische voorgeschiedenis werd door de huisarts verwezen naar de polikliniek Urologie in verband met pijnlijke erecties. Patiënt vertelde dat hij vier jaar geleden zelf kanamycinezalf in zijn penis geïnjecteerd had, met als doel zijn penis te vergroten. Bij navraag bleek hij destijds instructies te hebben gekregen van een vriend, die hetzelfde had gedaan. Sindsdien had patiënt progressieve klachten van oppervlakkige zwellingen en pijnlijke erecties. Bij genitaal onderzoek

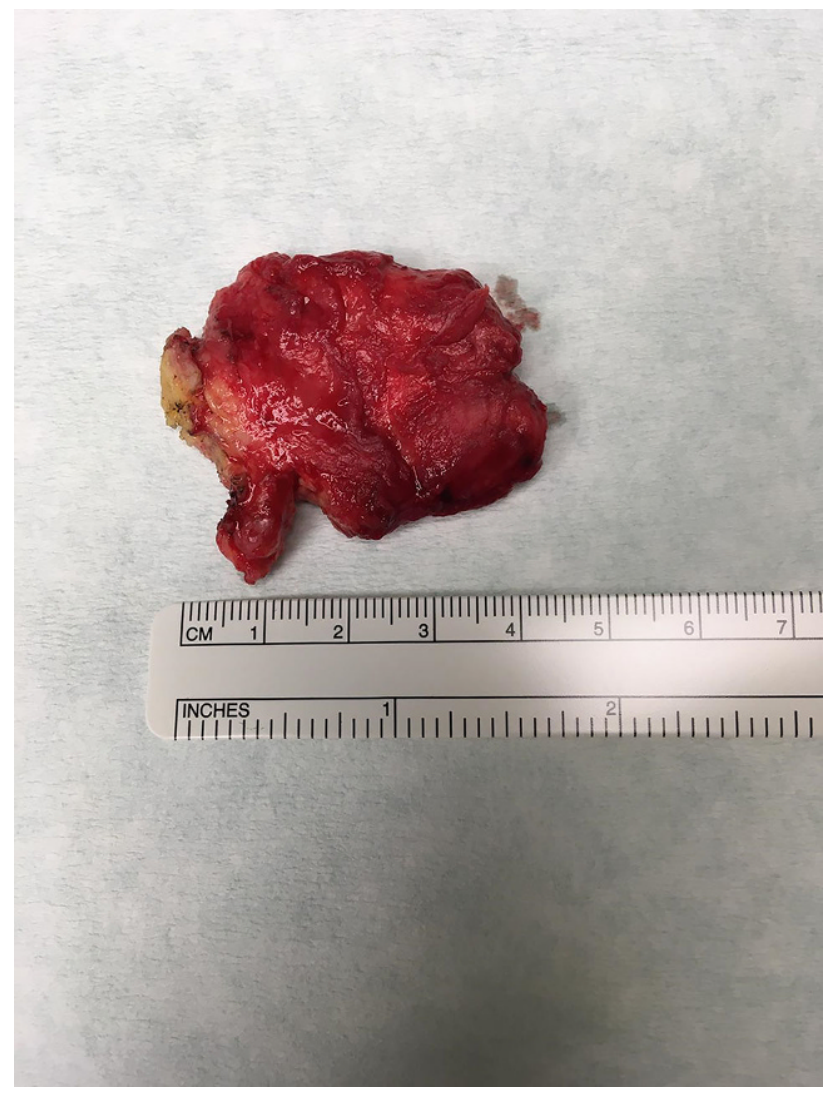

Figuur 2 Het gereseceerde weefsel van het penisparaffinoom

werd rechts in het preputium een forse fibromateuze plaque van circa $3 \mathrm{~cm}$ doorsnede gezien, losliggend van de corpora (fig. 1). Er vond chirurgische excisie van het granulatieweefsel plaats (fig. 2). Bij histopathologisch onderzoek was een uitgebreide fibrohistiocytaire stromareactie op lichaamsvreemd materiaal te zien.

\section{Discussie}

\section{Pathofysiologie}

Paraffinomen, ook wel scleroserende granulomen genoemd, ontstaan ten gevolge van injecties van vrij verkrijgbare olieachtige substanties, zoals paraffine, vaseline of siliconen in de subcutis. De term wordt gebruikt voor de beschrijving van een specifiek histopathologisch patroon, waarbij normaal subcutaan weefsel wordt vervangen door cysteuze ruimtes van verschillende grootte, die zijn gevuld met de geïnjecteerde substantie. Het lichaam reageert op deze substantie met de vorming van een vreemdlichaamgranuloom; een ontstekingsreactie met lymfocytaire infiltraten waarin zich meerkernige reuscellen bevinden. Complicaties ontstaan ten gevolge van het feit dat menselijk weefsel niet beschikt over enzymen om interstitiële exogene oliën te metaboliseren [1]. 


\section{Geschiedenis en epidemiologie}

Het injecteren van olieachtige substanties in het lichaam is een oude techniek voor het vergroten van structuren, en esthetische doeleinden, zoals het opvullen van imperfecties. In 1899 werd de eerste genitale injectie met paraffine verricht in het scrotum van een man na een bilaterale orchidectomie [2]. Het onmiddellijke cosmetische effect op de contour en het volume, de lage kosten en relatief pijnloze toepassing stimuleerden de toepassing in andere lichaamsdelen. In Oost-Europese en Aziatische culturen werden de injecties populair vanwege het feit dat een grote penis in deze culturen als een symbool van macht wordt gezien. Om diezelfde reden werden de injecties vanaf het begin van de $20^{\mathrm{e}}$ eeuw ook veel toegepast in gevangenissen $[3,4]$. Vanwege de complicaties, zoals infecties, huidnecrose en erectiele disfunctie, werd het gebruik door zorgprofessionals verlaten. Recente rapportages komen vooral uit Oost-Europa en Azië, waar de procedure in de privésfeer door niet-medici of door middel van zelfinjectie wordt verricht [5]. Tot dusver zijn wereldwijd 124 casus met peniele paraffinomen gerapporteerd, waarvan $34 \%$ optrad in Oost-Europa en $32 \%$ in Korea [6]. Wij zagen het afgelopen jaar twee patiënten van Oost-Europese afkomst na zelfinjectie van kanamycine met ernstige complicaties.

Tot op heden heeft de Amerikaanse Food and Drug Administration geen van de beschreven substanties of injectietechnieken goedgekeurd voor penisaugmentatie en kan de procedure niet in een legale setting worden verricht. Alleen een materiaal dat biocompatibel, niet-pyrogeen, niet-inflammatoir, niet-toxisch en niet-migrerend is, zou eventueel geschikt zijn, mits dit materiaal bovendien stabiel is na gebruik, eenvoudig toe te dienen en niet te duur zou zijn.

\section{Klinisch beeld}

Het klinisch beeld is niet alleen het gevolg van uitgebreide fibrosering, maar ook van obstructie van lymfedrainage, die wordt veroorzaakt door aanwezigheid van het niet-absorbeerbare materiaal in lymfeklieren. Differentiaaldiagnostisch moet worden gedacht aan seksueel overdraagbare aandoeningen met granuloomvorming en - bij oudere mannen aan plaveiselcelcarcinoom. De meest voorkomende symptomen ten gevolge van paraffinomen van de penis zijn: pijn en zwelling $(30 \%)$, ulceratie met fistelvorming (15\%) en malformatie (11\%) [6]. Verder komen voor: abces, gangreen, pijnlijke erecties, erectiele disfunctie, fimose en parafimose, huidnecrose, inguïnale lymfadenopathie en mictieproblemen.

Uit een recentelijk uitgevoerde grote serie blijkt, net als in onze casus, dat het tijdstip van symptoompresentatie sterk varieert: van een paar dagen tot 30 jaar na injectie [7]. Hierbij moet de kanttekening geplaatst worden dat de tijd tussen de injectie en de presentatie niet noodzakelijkerwijs identiek is aan de tijd tussen de injectie en het ontstaan van complicaties.

\section{Beeldvorming}

Voor het stellen van de diagnose is beeldvorming niet noodzakelijk. Wel kan het helpen om de mate van weefselinvasie van het granuloom in kaart te brengen. Bij echografie worden hypo-echogene laesies met slagschaduw en een verdikte subcutis beschreven. Het MRI-beeld wordt beschreven als een laagintens T1- en T2-gewogen signaal met minimale contrastoplichting [8]. Er is geen bewijs welk van beide technieken superieur is, maar preoperatief geeft een MRI-scan meer anatomische informatie.

\section{Behandeling}

Vanwege de klachten die patiënten hebben, wordt in een minderheid van de gevallen gekozen voor een conservatieve behandeling. In sommige gevallen is een circumcisie voldoende, maar definitieve behandeling bestaat uit volledige chirurgische excisie van de betrokken huid in een zo vroeg mogelijk stadium na injectie. Eventuele reconstructies zijn afhankelijk van de uitgebreidheid van het huiddefect en kunnen bestaan uit split skin grafts of bilaterale scrotale huidflappen [9]. Complete excisie is niet altijd mogelijk. In die gevallen kunnen restmateriaal in de fascie van Buck en lymfeklierweefsel leiden tot recidiverende klachten, zoals huidnecrose en fistels.

Hoewel paraffinomen niet vaak voorkomen, is het belangrijk dat zorgprofessionals zich bewust zijn van het bestaan van dit fenomeen, omdat patiënten vaak terughoudend zijn met het melden van (het ontstaan van) hun klachten, vanwege het taboe dat erop rust.

\section{Conclusie}

Vanwege de destructieve gevolgen is zelfinjectie van olieachtige substanties met als doel vergroting van de penis relatief zeldzaam. Desondanks vinden kanamycine-injecties in met name Oost-Europese landen en Azië nog geregeld plaats, met paraffinomen en erger tot gevolg. De behandeling bestaat uit volledige chirurgische excisie van het granuloom.

Open Access This article is distributed under the terms of the Creative Commons Attribution 4.0 International License (http://creativecommons.org/licenses/by/4.0/), which permits unrestricted use, distribution, and reproduction in any medium, provided you give appropriate credit to the original author(s) and the source, provide a link to the Creative Commons license, and indicate if changes were made.

\section{Literatuur}

1. Urbach F, Wine SS, Johnson WC, Davies RE. Generalized paraffinoma (sclerosing lipogranuloma). Arch Dermatol. 1971;103(3):277-85. 


\section{Case Report}

2. Gersuny R. Harte und weiche Paraffinprothesen. Zentralbl Chir. 1903;30:1.

3. Pehlivanov G, Kavaklieva S, Kazandijeva J, et al. Foreignbody granuloma of the penis in sexually active individuals (penile paraffinoma). J Eur Acad Dermatol Venereol. 2008;22:845-51.

4. Serour F. Artificial nodules of the penis. Report of six cases among Russian immigrants in Israel. Sex Transm Dis. 1993;20:192-3.

5. Kim DS, Choi HY. Penile paraffinoma: 39 cases. Korean J Urol. 1992;33:551.

6. DowneyAP, Osman NI, MangeraA, etal. Penileparaffinoma. Eur Urol Focus. 2019;5(5):894-8.

7. Svensøy JN, Travers V, Osther PJS. Complications of penile self-injections: investigation of 680 patients with compli- cations following penile self-injections with mineral oil. World J Urol. 2018;36:135-43.

8. Cormio L, Di Fino G, Scavone C, et al. Magnetic resonance imaging of penile paraffinoma: case report. BMC Med Imaging. 2014;14:39.

9. Jeong JH, Shin HJ, Woo SH, et al. A new repair technique for penile paraffinoma: bilateral scrotal flaps. Ann Plast Surg. 1996;37:386-93.

Leonie Exterkate, arts-onderzoeker

Jean-Paul A. van Basten, uroloog 